\title{
O Uso dos Espaços Urbanos pelas Crianças: Explorando o Comportamento do Brincar em Praças Públicas
}

\author{
Use of Urban Spaces by Children: Exploring the Behavior of Playing \\ in Public Squares
}

\author{
Giordana Machado da Luz ${ }^{*}$ a \& Ariane Kuhnen ${ }^{b}$ \\ ${ }^{a}$ Escola Superior de Criciúma, Criciúma, Santa Catarina, Brasil \\ $\&{ }^{b}$ Universidade Federal de Santa Catarina, Florianópolis, Santa Catarina, Brasil
}

\begin{abstract}
Resumo
O acesso aos espaços públicos tem estado cada vez mais restrito devido às mudanças sociais e espaciais. Contudo, é importante por oportunizar às crianças o desenvolvimento de habilidades físicas, cognitivas, sociais e psicológicas, através da atividade do brincar. Esta pesquisa objetivou investigar de que forma as características sócio-físicas do espaço público intervêm no comportamento de crianças. Para tanto foram realizadas observações de crianças de 6 a 12 anos, através da técnica de mapeamento comportamental centrado-na-pessoa, em quatro praças da cidade de Criciúma, Estado de Santa Catarina. Os resultados apontam que um ambiente seguro, diversificado e flexível possibilita não apenas a atividade física e a socialização, mas favorece habilidades cognitivas e psicológicas ao influenciar no tipo de brincadeira e nível de interação entre as crianças.

Palavras-chave: Espaço, desenvolvimento infantil, psicologia ambiental, mapeamento comportamental.
\end{abstract}

\begin{abstract}
Access to public spaces has been shown to be increasingly restricted due to spatial and social changes. However, these public spaces are important for developing motor, social, cognitive and affectionate skills. This research aims to investigate the socio-physical characteristics of public spaces that interfere in children's behavior. Data were collected from observations with children between 6 and 12 years old, through a self-centered behavioral mapping, in four public spaces in the city of Criciúma, Santa Catarina. The results indicate that a secure, diverse and flexible environment allows not only physical activity and socialization, but it also favors psychological and cognitive skills that influence the type of game and the level of interaction among children.

Keywords: Space, childhood development, environmental psychology, behavioral mapping.
\end{abstract}

O uso do espaço público foi se modificando ao longo dos séculos a partir de mudanças sociais, econômicas e espaciais. A rua, outrora espaço de socialização e brincadeira, foi tornando-se espaço de perigo, principalmente para as crianças. No século XX foram criadas as praças e os parques públicos como alternativas de lazer e locais de brincadeira (Oliveira, 2004). Atualmente não são considerados seguros, pois nem sempre obedecem às normas de segurança quanto à instalação e manutenção dos equipamentos (Harada, Pedreira, \& Andreoti, 2003) e, por vezes, são utilizadas para fins ilícitos.

Os espaços públicos como as praças e os parques infantis, além do papel de socialização, mostram-se im-

\footnotetext{
* Endereço para correspondência: Avenida Victor Meireles, 350, apto 602, Centro, Criciúma, SC, Brasil 88802-050. E-mail: giordana32@gmail.com e ariane@ cfh.ufsc.br
}

portantes para o desenvolvimento infantil por oportunizar habilidades físicas (força, agilidade, motricidade ampla), cognitivas (concentração, atenção, noção espacial), sociais (interação, socialização, diversidade) e psicológicas (regular emoções, criatividade, autonomia), através da atividade do brincar (Souza \& Vieira, 2004).

O brincar é um comportamento que foi selecionado pela espécie; contudo sofre influência de fatores culturais, sociais, econômicos e espaciais, modificando-se no tempo e no espaço (Valentine \& Mckendrick, 1997). Neste sentido, o comportamento do brincar pode ser inibido ou estimulado dependendo das características do espaço onde ocorre. Desta forma, o desenvolvimento psicológico ocorre conforme a pessoa se envolve ativamente com o ambiente físico e social, o compreende e o interpreta, pois "diferentes tipos de ambientes dão origem a padrões distintivos de papéis, atividades e relações para as pessoas que se tornam participantes nestes ambientes" (Bronfenbrenner, 1999, p. 17). 
Além disso, as pessoas não investem afetivamente em todo ou qualquer lugar, mas nos que apresentam características/oportunidades de satisfazer suas necessidades pessoais (Kuhnen, 2009). Assim, o apego a um dado lugar pode se modificar dependendo da fase do desenvolvimento psicológico em que a pessoa se encontra, pois cada fase demanda necessidades distintas (Sommer, 1990). Partindo do conceito de apego ao lugar, Rasmussen (2004) - com base na observação de atividades infantis em espaços públicos variados, chamou "espaços para crianças" (places for children) àqueles planejados pelos adultos e "espaços das crianças" (children's places) àqueles apropriados por elas. Neste sentido, mesmo em um espaço planejado para atividades infantis, existem áreas escolhidas, apropriadas e ressignificadas pelas crianças, transformando-se em espaço da criança.

A escolha/preferência por um dado espaço em detrimento de outro está relacionada aos atributos ambientais (espacial, físico e social) oferecidos e percebidos por seus usuários. Estes atributos influenciam também na forma como o espaço é utilizado, em termos de frequência e variedade de comportamentos, sobretudo em grupo (Min \& Lee, 2006). O espaço é ainda percebido a partir da avaliação de características positivas e negativas. As crianças percebem negativamente os lugares que são centros de risco e como positivos os locais que garantem oportunidades de atividade física e interação social, presença de comércio alimentício e espaço verde (Castonguay \& Jutras, 2008; Hume, Salmon, \& Ball, 2005).

Um dos atributos dos espaços ao ar livre que tem sido investigado é a presença de vegetação e sua relação com o desenvolvimento infantil. A presença de vegetação em áreas de brincadeira ao ar livre como playgrounds, praças, vizinhança tem sido associada ao aumento no nível de interação e diversidade nos tipos de brincadeira (Barbou, 1999; Fjùrtoft \& Sageie, 2000; Herrington \& Studtmann, 1998). Além de estimular as habilidades sociais, os ambientes naturais parecem melhorar a função cognitiva (atenção), estimular a atividade lúdica e a criatividade e diminuir os efeitos negativos dos eventos de estresse (Wells, 2000). Outro aspecto importante que tem sido relacionado à presença de vegetação é o de auxiliar no contato com o espaço ao ar livre, aumentando o nível de atividade física e, consequentemente, prevenindo a obesidade infantil (Bell, Wilson, \& Liu, 2008; Janice, Jeffrey, \& Gilbert, 2008). Neste sentido, a presença de vegetação assume um papel de facilitador no acesso das crianças a tais espaços, uma vez que os torna mais atrativos (Faber Taylor \& Kuo, 2009).

Outro aspecto que torna mais atrativo os espaços ao ar livre, sobretudo playgrounds, pátios escolares e praças públicas, diz respeito ao design proposto: a estrutura apresentada nesses espaços e sua disposição influenciam no desenvolvimento de habilidades sociais, atuando sobre a socialização e a capacidade de resolver situações de conflitos, assim como, a escolha do tipo de brincadeira (Sager, Sperb, Roazzi, \& Martins, 2003). Também as habilidades físicas podem ser facilitadas dependendo do tipo de equipamento presente no playground ou na praça, sendo que os multifuncionais são os preferidos por permitirem mais atividade física e oportunidade de brincadeira entre as crianças (Fernandes \& Elali, 2008; Raymundo, Kuhnen, \& Soares, 2010; Ridgers, Stratton, Fairclough, \& Twisk, 2007). Podemos pensar que os tipos de equipamento e sua disposição tornam-se importantes por facilitar ou não o desenvolvimento de habilidades, através da interação e da atividade física entre as crianças.

Os estudos citados demonstram que as crianças têm preferências em relação aos espaços que utilizam para brincar e se exercitar e que tais preferências dependem das características pessoais, como idade, mas também dos atributos físicos e sociais que os espaços oferecem. As características dos espaços podem influenciar ainda no tipo de interação social e na intensidade de atividade realizada, demonstrando a importância potencial dos ambientes para promover comportamentos de socialização, exploração, autonomia e atividade física.

Ao passo que na literatura torna-se cada vez mais evidente a importância do espaço urbano para o desenvolvimento físico, cognitivo, social e psicológico do ser humano, a falta de acesso aos espaços, sobretudo os públicos, também se evidencia através do aumento da violência, do tráfego de veículos e da falta de estrutura disponibilizada, trazendo prejuízo à saúde e à maturação infantil. A falta de acesso e uso dos espaços urbanos, nesse sentido, torna-se não apenas um problema espacial, mas um problema de saúde física e psicológica que precisa ser melhor compreendido. Assim, torna-se relevante investigar de que forma a qualidade dos espaços urbanos, principalmente os públicos, intervém no comportamento do brincar a fim de contribuir para o desenvolvimento saudável de seus usuários.

\section{Método}

A pesquisa teve caráter descritivo e exploratório e pretendeu caracterizar dimensões espaciais e pessoais, envolvidas na relação entre desenvolvimento infantil e o espaço público. A metodologia de pesquisa envolveu o uso de multimétodos. A abordagem multimétodos abarca o uso de várias técnicas, ora centradas no ambiente, ora na pessoa, no sentido de tentar abranger o máximo possível de aspectos do fenômeno estudado e integrar, de forma prática e teórica, os achados das pesquisas científicas (Günther, Elali, \& Pinheiro, 2008). Os estudos de Fernandes e Elali (2008) e Raymundo et al. (2010) são exemplos de uso desta abordagem, ao analisarem o comportamento infantil em pátios escolares.

O mapeamento comportamental é "uma técnica de pesquisa que explora a associação entre fenômenos comportamentais e o ambiente em que ocorrem" (Pinheiro, Elali, \& Fernandes, 2008, p. 83). Nesta pesquisa foi realizado estudo preliminar, com o intuito de mapear o ambiente através de visitas de reconhecimento e avaliação das condições físicas das praças. O mapeamento comportamental 
centrado na pessoa foi a técnica escolhida para estudo dos comportamentos das crianças, através da representação da área observada, definição dos comportamentos, esquema de registro e codificação dos eventos observados.

\section{Contextos de Coleta}

A pesquisa foi realizada em quatro praças públicas da cidade de Criciúma, sul do Estado de Santa Catarina. As praças foram selecionadas de acordo com três critérios: (a) conterem espaço de lazer infantil - playground, quadra poliesportiva ou pista de skate; (b) localização geográfica - representarem uma região; (c) estarem ocupadas/em uso no momento da coleta. As praças foram denominadas de P1, P2, P3 e P4 para facilitar a compreensão do leitor, sendo a P2 localizada no centro da cidade e as demais em regiões periféricas. A $\mathrm{P} 1, \mathrm{P} 3 \mathrm{e} \mathrm{P} 4$ podem ser caracterizadas como praças pequenas - até $3.000 \mathrm{~m}^{2}$, e a $\mathrm{P} 2$ como praça grande - acima de $5.000 \mathrm{~m}^{2}$ (Fedrizzi, 2002).

\section{Participantes}

Participaram da pesquisa 40 crianças, sendo 20 do sexo masculino e 20 do sexo feminino, com idades entre 6 e 12 anos, sendo 12 meninos e meninas de 6 a 9 anos e 8 meninos e meninas de 10 a 12 anos. A média de idade foi de 8 anos e 8 meses. As crianças se encontravam brincando nas praças públicas pesquisadas.

\section{Procedimentos}

O projeto de pesquisa foi aprovado pelo Comitê de Ética da Universidade Federal de Santa Catarina (UFSC).

Estudo Preliminar: Centrado no Ambiente. Um estudo preliminar foi realizado com o intuito de conhecer e selecionar as praças para coleta de dados. As quatro praças selecionadas foram avaliadas quanto à: disponibilidade de equipamentos, manutenção, vegetação e segurança. Além do registro de informações as praças foram fotografadas.

Mapeamento Comportamental Centrado na Pessoa. $\mathrm{O}$ processo iniciou com a preparação dos instrumentos de coleta necessários ao mapeamento comportamental: croquis das praças e formulário de registro das observações. Durante as visitas as praças fizeram-se observações livres e registros em diário de campo, com informações pertinentes para a construção do formulário de registro e fluxo de registro das observações.

O mapeamento ocorreu desde a chegada das crianças ao local até o término de suas atividades, o que levou de alguns minutos a mais de uma hora, dependendo da criança. Em seguida, se dava a aproximação da pesquisadora para a apresentação do TCLE - Termo de Consentimento Livre e Esclarecido, aos responsáveis, e obtenção de dados como idade, local de residência e distância.

Teste Piloto e de Concordância. A fim de adequar os instrumentos e garantir maior fidedignidade dos dados coletados no mapeamento comportamental centrado na pessoa, o formulário de registro das observações, assim como sua forma de aplicação, passaram por teste piloto e de concordância. Durante os testes uma mesma criança, escolhida aleatoriamente, foi observada por duas pesquisadoras, durante intervalo de tempo pré-determinado. Ao final, os registros foram comparados para levantar o total de acertos e erros (acerto $=$ mesmo comportamento registrado numa sequência e intervalo de tempo; erro $=$ diferente comportamento registrado). Foram realizados dois testes de concordância, com o auxílio de uma pesquisadora colaboradora, em duas praças distintas, com resultados de $71,4 \%$ e $80 \%$.

\section{Análise dos Dados}

Os dados coletados sobre as praças públicas foram analisados a partir da frequência de cada categoria de análise, visando-se obter um panorama geral das condições de planejamento (acesso, tipos de equipamentos, manutenção), segurança e condições físicas (vegetação) de cada local. Os dados obtidos a partir do mapeamento comportamental foram documentados graficamente nas plantas baixas das quatro praças e, após, digitalizados através do programa Adobe Photoshop Image versão 9.0, elegendo-se o uso de uma cor distinta para cada criança em estudo. As variáveis como sexo, idade, tipo de atividade, tempo de permanência e ocupação, foram tratados e tabulados através do programa Excel. As atividades/brincadeiras encontradas foram agrupadas conforme o tipo de ação predominante, sendo as categorias criadas previamente a partir de observações e anotações em diário de campo.

\section{Resultados}

\section{Estudo Preliminar: Conhecendo as Praças}

Com o estudo preliminar foi possível conhecer os recursos de lazer presentes nas praças, assim como, o estado de manutenção das mesmas. Como recursos de lazer entendem-se: a disponibilidade quantitativa e qualitativa de equipamentos de playground, de quadra poliesportiva e de pista de skate. O parque infantil é uma estrutura planejada e presente em todas as praças pesquisadas, como pode ser observado na Tabela 1.

Tabela 1

Tipo de Equipamentos Presentes nas Praças

\begin{tabular}{|c|c|c|c|c|c|}
\hline \multirow{2}{*}{$\begin{array}{l}\text { Tipo de } \\
\text { Equipamento }\end{array}$} & \multicolumn{4}{|c|}{ Praça } & \multirow{2}{*}{ Total } \\
\hline & $\mathrm{P} 1$ & $\mathrm{P} 2$ & P3 & $\mathrm{P} 4$ & \\
\hline Balanço & 2 & 1 & 1 & 2 & $6(27,3 \%)$ \\
\hline Escorregador & 2 & 2 & 1 & 1 & $6(27,3 \%)$ \\
\hline Gangorra & 2 & 2 & 1 & 1 & $6(27,3 \%)$ \\
\hline Gira-gira & 0 & 1 & 1 & 0 & $2(9,1 \%)$ \\
\hline Vai-e-vem & 0 & 1 & 0 & 0 & $1(4,5 \%)$ \\
\hline Ponte & 0 & 1 & 0 & 0 & $1(4,5 \%)$ \\
\hline Total & 6 & 8 & 4 & 4 & $22(100 \%)$ \\
\hline
\end{tabular}


Luz, G. M. \& Kuhnen, A. (2013). O Uso dos Espaços Urbanos pelas Crianças: Explorando o Comportamento do Brincar em Praças Públicas.

Os equipamentos tradicionais como balanço, gangorra e escorregador, são os mais frequentes, sendo encontrados em todos os contextos de coleta. Os demais equipamentos, incluindo os multifuncionais, são disponibilizados apenas na P2. A P2 difere quantitativa e qualitativamente das demais praças, pois possui um número maior de equipamentos, além de mais diversificados. As P1 e P4 dispõem de uma estrutura mais tradicional, composta apenas por balanço, gangorra e escorregador. A P3 é um espaço multiatrativo que apresenta playground, quadra poliesportiva e pista de skate, ampliando as possibilidades de atividades.

$\mathrm{Na}$ manutenção da estrutura das praças, os tópicos avaliados foram condição da pintura, do piso, da marcação territorial por cercas, da limpeza, da poda e corte da grama, peças quebradas e/ou ausentes, como observado na Tabela 2.

Tabela 2

Condição de Manutenção das Praças

\begin{tabular}{lcccc}
\hline \multirow{2}{*}{ Manutenção } & \multicolumn{4}{c}{ Praça } \\
\cline { 2 - 5 } Pintura descascada & P1 & P2 & P3 & P4 \\
Piso desgastado & X & X & X \\
Cerca quebrada & & & X \\
Local sujo & X & & X & X \\
Vegetação alta & & & X & \\
Peças ausentes & X & X & & X \\
Peças quebradas & X & X & X & X \\
\hline Total & 4 & 3 & 4 & 4 \\
\hline
\end{tabular}

Neste sentido, foram consideradas com bom estado de manutenção as praças que pontuaram em até um item; com razoável as que pontuaram de 2 a 3 itens e com ruim as que apresentaram de 4 a 7 itens. Os dados demonstram que a P2 estava em estado de manutenção razoável, enquanto que nas demais o resultado de manutenção era ruim. Pode-se observar que alguns tópicos referentes à manutenção, como peças quebradas, dificultam não apenas o brincar, mas aumentam o risco de acidentes. Percebe-se, então, que a P2 apresenta melhores condições de uso ou menos riscos físicos as crianças que as demais praças.

As características físicas também foram avaliadas, sendo quantificada a presença de vegetação, a partir do número de árvores e arbustos no local, assim como, de sombra produzida na área total da praça. A P2 e P4 apresentaram muita vegetação, enquanto que a P1 e P3 possuíam pouca vegetação.

\section{Mapeamento Comportamental Centrado na Pessoa: Brincando e Ocupando as Praças}

A partir das observações em diário de campo, foram criadas 13 categorias de observação de acordo com as atividades e/ou comportamentos realizados pelas crianças: (a) desocupado; (b) observando; (c) descansando; (d) conversando; (e) brincadeira turbulenta (correr, subir, pular); (f) brincadeira com elementos naturais (brincar com areia, vegetação, água); (g) brincadeira nos equipamentos (balanço, escorregador, etc.); (h) jogos em grupo (pega-pega, esconde-esconde, passar anel, etc.); (i) jogos com bola (futebol, vôlei, etc.); (j) brincadeiras de locomoção (bicicleta, skate, patins); (k) brincadeira com brinquedo próprio (boneca, carrinho, etc.); (l) comer/beber; (m) cuidando/ ajudando outra criança (empurrando o balanço, etc.).

O mapeamento comportamental centrado na pessoa permitiu levantar dados sobre o uso das praças através: dos trajetos realizados, dos setores utilizados, das atividades desenvolvidas e do tempo dispensado nos locais. A partir da análise dos dados percebe-se que as praças foram ocupadas diferentemente em relação ao sexo e faixa etária das crianças pesquisadas, como ilustrado na Tabela 3:

Tabela 3

Número de Participantes por Sexo e Faixa Etária em cada Praça

\begin{tabular}{|c|c|c|c|c|c|c|c|c|c|}
\hline \multirow[b]{3}{*}{ Faixa Etária/Gênero } & \multicolumn{7}{|c|}{ Praças } & & \multirow[b]{3}{*}{ Total } \\
\hline & \multicolumn{2}{|c|}{$\mathrm{P} 1$} & \multicolumn{2}{|c|}{$\mathrm{P} 2$} & \multicolumn{2}{|c|}{ P3 } & \multicolumn{2}{|c|}{$\mathrm{P} 4$} & \\
\hline & $\mathrm{M}$ & $\mathrm{F}$ & $\mathrm{M}$ & $\mathrm{F}$ & $\mathrm{M}$ & $\mathrm{F}$ & $\mathrm{M}$ & $\mathrm{F}$ & \\
\hline $6-9$ anos & 3 & 2 & 4 & 5 & 3 & - & 1 & 6 & 24 \\
\hline $10-12$ anos & 1 & 4 & - & 1 & 6 & 1 & 2 & 1 & 16 \\
\hline Total & 4 & 6 & 4 & 6 & 9 & 1 & 3 & 7 & 40 \\
\hline
\end{tabular}

A P1, P2 e P4 apresentam maior número de participantes do sexo feminino e a $\mathrm{P} 3$, ao contrário, possui número maior de participantes do sexo masculino. Dentre os participantes, foi superior a presença de crianças na faixa etária de 6 a 9 anos $(60 \%)$ em relação a de 10 a 12 anos (40\%). Na P2 e P4 a presença de crianças na faixa etária de 6 a 9 anos foi superior, $90 \%$ e $70 \%$ do total, respectivamente. $\mathrm{Na}$ P1 a participação das faixas etárias foi idêntica, totalizando $50 \%$ de 6 a 9 anos e $50 \%$ de 10 a 12 anos. Na P3, ao contrário, a faixa etária mais frequente foi de 10 a 12 anos $(70 \%$ do total). A partir da análise dos dados observados, percebeu-se que as características pessoais podem influir na escolha da atividade e modo de ocupação nas praças. 


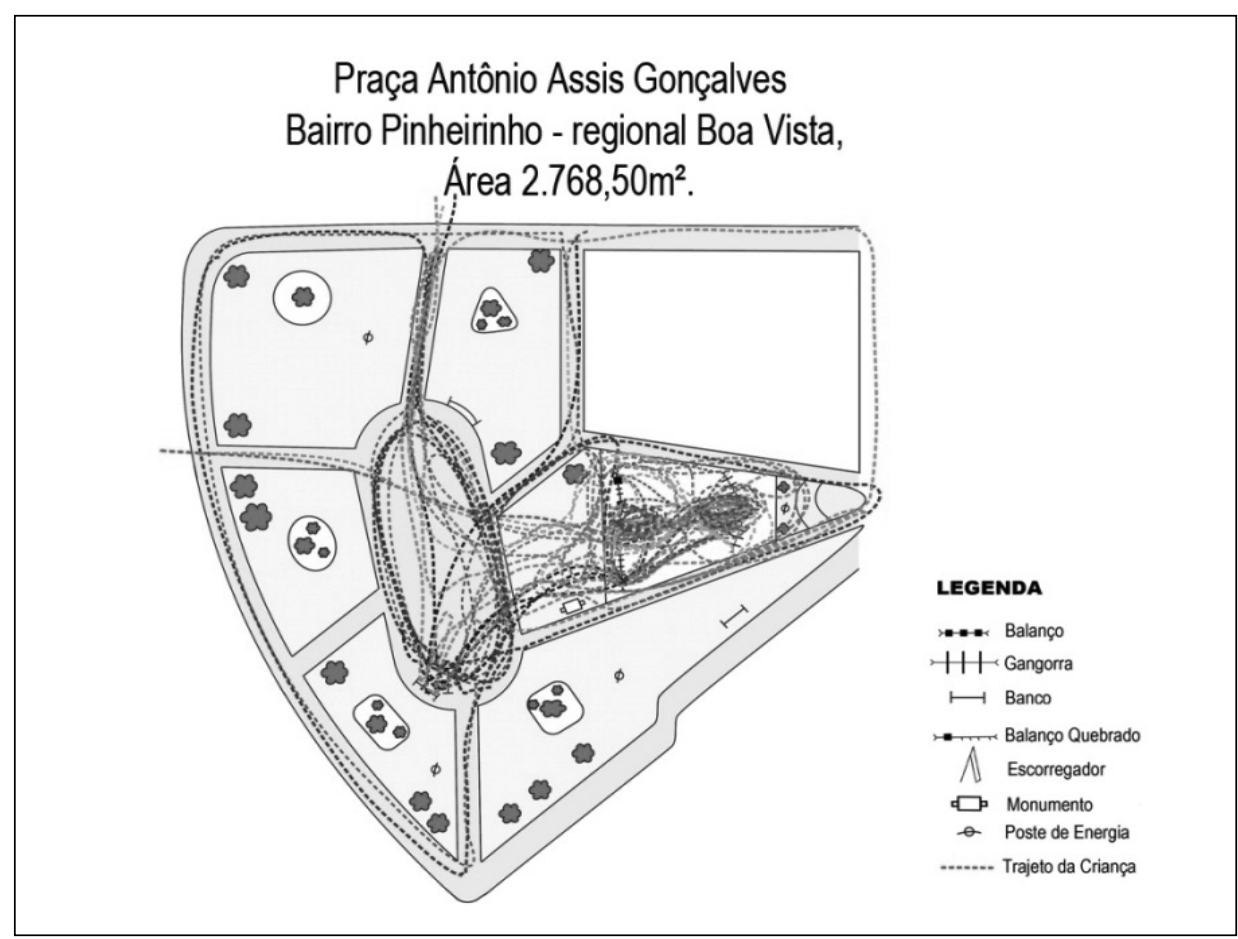

Figura 1. Mapa dos Trajetos das Crianças Observadas na P1.

Analisando os trajetos realizados verifica-se que diferentes espaços são explorados em cada praça. A título de ilustração, a Figura 1 apresenta o exemplo do procedimento na P1.

Praticamente toda a extensão da P1 foi explorada, principalmente o parque e a área livre. O parque é pequeno em relação à praça, o que pode estimular as crianças a explorarem a área livre; além disso, a estrutura planejada dispõe de poucos equipamentos. A área livre parece ter sido utilizada quando as crianças queriam desenvolver atividades que necessitavam de um espaço mais amplo como andar de bicicleta, correr.

$\mathrm{Na}$ P2 a área mais explorada foi o playground. Apesar da extensão espacial, as áreas livres são pouco exploradas, indicando que o contexto foi utilizado quase que exclusivamente para a atividade de brincadeira nos equipamentos. $O$ resultado pode ser explicado pela estrutura planejada disponível nesta praça que, como apresentado na avaliação dos ambientes, é melhor em termos de diversidade de equipamentos e manutenção.

Os trajetos na $\mathrm{P} 3$ se concentram na quadra poliesportiva, área mais explorada em relação ao parque e a pista de skate. Acredita-se que o gênero e a idade dos participantes influenciaram neste resultado, uma vez que os participantes eram $90 \%$ do sexo masculino, com faixa etária predominante de 10 a 12 anos (60\%). O espaço foi utilizado quase que exclusivamente para o jogo de futebol. A única menina que utilizou a praça se concentrou no playground.

$\mathrm{Na}$ P4 o espaço mais explorado foi o parque infantil, contudo as áreas próximas também foram utilizadas com frequência, como uma grande árvore da espécie figueira.
A figueira serve como local de descanso e conversação, mas, principalmente, como equipamento de brincadeira onde ficam penduradas. O playground possui poucos equipamentos e alguns estão quebrados, o que faz com que as crianças, às vezes, precisem aguardar vaga. Isto pode explicar o porquê algumas crianças prefiram utilizar a figueira para brincar.

Além dos trajetos de cada criança, foram registradas todas as atividades desenvolvidas pelos participantes durante o mapeamento comportamental, assim como o tempo de permanência em cada atividade. Dentre as atividades observadas foram utilizadas para análise somente as atividades principais, ou seja, a atividade em que cada criança desenvolveu por mais tempo em cada praça, como mostra a Tabela 4.

De forma geral, a atividade principal realizada pelas crianças foi brincar nos equipamentos, com $50 \%$ do total das atividades observadas, seguido do brincar com bola, com $22,5 \%$ do total. Comparando cada praça, observa-se que a P1 e P4 apresentaram o mesmo índice no uso dos equipamentos ( $50 \%$ do total). Na P1 a segunda atividade mais presente foi o brincar com brinquedo próprio, este dado pode sugerir que, por falta de uma estrutura mais diversificada, as crianças acabem levando seus brinquedos. Além disso, a condição de conservação dos equipamentos é muito ruim, como avaliada no estudo preliminar. $\mathrm{Na} \mathrm{P} 4$ a segunda atividade mais frequente foi o brincar em grupo, o que, neste caso, pode indicar que também a estrutura do parque não é tão atrativa. 
Luz, G. M. \& Kuhnen, A. (2013). O Uso dos Espaços Urbanos pelas Crianças: Explorando o Comportamento do Brincar em Praças Públicas.

Tabela 4

Número de Participantes por Praça e Atividade Principal

\begin{tabular}{lccccc}
\hline \multirow{2}{*}{ Atividade Principal } & \multicolumn{3}{c}{ Praça } & Total \\
\cline { 2 - 5 } & P1 & P2 & P3 & P4 & \\
\hline Equipamentos & 5 & 9 & 1 & 5 & $20(50 \%)$ \\
Observar & 0 & 0 & 1 & 0 & $1(2,5 \%)$ \\
Conversar & 2 & 0 & 0 & 0 & $2(5 \%)$ \\
Elementos naturais & 0 & 0 & 0 & 2 & $2(5 \%)$ \\
Brinquedo próprio & 3 & 0 & 0 & 0 & $3(7,5 \%)$ \\
Brincar em grupo & 0 & 0 & 0 & 3 & $3(7,5 \%)$ \\
Brincar com bola & 0 & 1 & 8 & 0 & $9(22,5 \%)$ \\
\hline Total & 10 & 10 & 10 & 10 & $40(100 \%)$ \\
\hline
\end{tabular}

Na P2 e P3 a preferência das crianças foi pelo uso dos espaços planejados para brincadeira. Na P2 90\% das crianças passaram a maior parte do tempo brincando no playground. $\mathrm{O}$ resultado pode ser explicado pelos equipamentos mais diversificados e melhor conservados, quando comparados aos equipamentos das demais praças. $\mathrm{Na} \mathrm{P} 3$ a principal atividade foi o brincar com bola $(80 \%)$, sendo que o espaço planejado mais utilizado foi a quadra poliesportiva. O resultado pode ser explicado pelo mau estado de conservação do playground e pelo perfil da maioria dos usuários (meninos de 10 a 12 anos). Pode-se pensar que a atividade de brincar com bola seria mais frequente se as demais praças também dispusessem de quadra esportiva.
As demais categorias (desocupado; descansando; brincadeira turbulenta; brincadeiras de locomoção; comer/ beber; cuidando/ajudando outra criança) aparecem nas observações de forma geral, mas não estiveram dentre a atividade principal de nenhuma das crianças.

A atividade principal também foi analisada em função do sexo das crianças observadas. O uso dos equipamentos do playground foi mais frequente entre as meninas (65\%) do que entre os meninos (35\%), assim como o conversar e brincar em grupo. Em contrapartida, a atividade do brincar com bola ocorreu apenas entre os meninos, como mostra a Tabela 5 .

Tabela 5

Número de Participantes por Sexo e Atividade Principal

\begin{tabular}{lccc}
\hline \multirow{2}{*}{ Atividade Principal } & \multicolumn{2}{c}{ Sexo } & Total \\
\cline { 2 - 3 } & Masculino & Feminino & $20(50 \%)$ \\
\hline Equipamentos & 7 & 13 & $1(2,5 \%)$ \\
Observar & 1 & 0 & $2(5 \%)$ \\
Conversar & 0 & 2 & $2(5 \%)$ \\
Elementos naturais & 1 & 1 & $3(7,5 \%)$ \\
Brinquedo próprio & 2 & 1 & $3(7,5 \%)$ \\
Brincar em grupo & 0 & 3 & $9(22,5 \%)$ \\
Brincar com bola & 9 & 0 & $40(100 \%)$ \\
\hline Total & 20 & 20 & \\
\hline
\end{tabular}

Em relação aos setores, cada praça foi dividida em área de brincar (playground e quadra), área verde (árvores); área de estar (bancos) e área livre. Os dados tratados sobre os setores mais utilizados podem ser observados na Tabela 6 : 
Psicologia: Reflexão e Crítica, 26(3), 552-560.

Tabela 6

Número de Participantes por Praça e Setores Utilizados

\begin{tabular}{lccccc}
\hline Setores & \multicolumn{3}{c}{ Praça } & \multirow{2}{*}{ Total } \\
\cline { 2 - 5 } & P1 & P2 & P3 & P4 & \\
\hline Área de brincar & 10 & 10 & 9 & 10 & $39(56,5 \%)$ \\
Área verde & 0 & 5 & 0 & 9 & $14(20,3 \%)$ \\
Área livre & 4 & 3 & 2 & 4 & $13(18,8 \%)$ \\
Área estar & 2 & 0 & 0 & 1 & $3(4,4 \%)$ \\
\hline Total & $16(23,2 \%)$ & $18(26,1 \%)$ & $11(15,9 \%)$ & $24(34,8 \%)$ & $69(100 \%)$ \\
\hline
\end{tabular}

A área de brincar foi a mais utilizada em todas as praças, concentrando um índice de 56,5\%. A área verde foi a segunda mais utilizada, logo seguida pela área livre, com índices de $20,3 \%$ e 18,8\%, respectivamente. Contudo, observa-se que as áreas verdes foram utilizadas apenas na P2 e P4, principalmente na segunda, onde a vegetação é mais abundante. A P1 e P3 são praças pequenas, uma tendo pequena área planejada para atividades de lazer e a outra tendo toda a sua extensão planejada para tais atividades. Na primeira, as crianças exploram toda a extensão da praça; na segunda, as crianças tendem a se concentrar numa única atividade. Na P2, também com estrutura planejada, diversificada e ampla, as crianças tendem a se concentrar num mesmo setor e atividade. $\mathrm{Na} \mathrm{P} 4$, com estrutura pouco planejada, as crianças tendem a explorar outros setores.

\section{Discussão}

Apesar dos limites próprios de um estudo exploratório, a pesquisa buscou compartilhar com a perspectiva da abordagem ecológica, na qual a pessoa não pode ser investigada à parte do contexto de desenvolvimento. De acordo com Bronfenbrenner (1979/1996) cada ambiente atua de forma direta ou indireta sobre o desenvolvimento humano. Como cada ambiente possui características distintas pode-se dizer que cada um exerce uma função específica e, desta forma, complementar sobre o desenvolvimento humano. Os espaços urbanos, neste caso as praças, são compreendidos como ambientes de socialização e convívio coletivo que, a partir de características próprias, oferecem o treino de habilidades específicas, além de estimular o bem estar e a qualidade de vida de seus usuários. A influência exercida pelo ambiente, contudo, depende de suas características e da forma como essas interagem com as características das pessoas envolvidas, uma vez que o processo de interação não é estático, mas dinâmico.

Neste sentido, os resultados desta pesquisa indicam que as características de cada espaço intervêm nas variadas formas com que a criança se apropria do mesmo e, consequentemente, no tipo de interação e na escolha das brincadeiras realizadas, mas não são as únicas variáveis que interagem com o fenômeno do brincar. As características das crianças, como idade e sexo, também atuam nas escolhas e apropriações dos espaços, direcionando seu comportamento, como demonstram os dados.

Dentre as características sociais e físicas das praças investigadas, a disponibilidade de equipamentos e a manutenção parecem intervir no comportamento de uso dos espaços pelas crianças de forma mais forte que a presença de vegetação. Nas praças em que havia espaços planejados de forma direcionada e em condições de manutenção mais adequadas, as crianças permaneceram por mais tempo em uma mesma atividade e setor, ou seja, se concentraram por mais tempo brincando no playground e na quadra poliesportiva. Por outro lado, nos locais que apresentaram condições de manutenção e disponibilidade de equipamentos menos adequados, as crianças tenderam a explorar mais outros setores e a permanecer por menos tempo numa mesma brincadeira, sobretudo quando este mesmo local não dispunha de vegetação abundante. $\mathrm{O}$ playground foi menos utilizado e os tipos de atividades foram mais diversificadas, contudo o tempo dispensado nas brincadeiras também foi menor.

Os dados encontrados corroboram com os estudos de Fernandes e Elali (2008) e Raymundo et al. (2010), principalmente no que tange aos equipamentos disponibilizados nos locais. Os equipamentos multifuncionais foram os que propiciaram maior oportunidade de brincadeira e/ ou mobilidade as crianças. Concorda-se com as autoras que tais equipamentos são mais atrativos em relação aos tradicionais, pois promovem diferentes tipos de atividades em comparação aos que possuem apenas uma função.

Em relação à dimensão das praças pesquisadas, os dados encontrados não conferem com os achados de Sager et al. (2003), pois o tamanho da área só parece influenciar no tipo de atividade das crianças quando o local não dispõe de estrutura adequada em termos de equipamentos disponíveis e manutenção. Mesmo na P2 onde o espaço, além de amplo, conta com abundante vegetação, as crianças permaneceram por mais tempo no playground, indicando que a oferta de equipamentos e seu estado de conservação parecem afetar mais o comportamento infantil que a dimensão do espaço 
como um todo. Cabe ressaltar que mesmo nas praças pequenas, como a P3, a proporção área/usuário se mostrou generosa, ou seja, superior a $20 \mathrm{~m}^{2} /$ criança (Moore, 1996).

De acordo com os resultados da pesquisa, a quantidade e o tipo de equipamento das praças, bem como seu estado de conservação, intervêm no tipo de atividade realizada e tempo dispensado na mesma, mas não necessariamente no nível de atividade física das crianças e no tempo de permanência total nos espaços, como demonstrado também no estudo de Ridgers et al. (2007). Nas praças que dispunham de um ambiente mais pobre em termos de quantidade e qualidade de equipamentos e manutenção, a criança permanecia por menos tempo numa mesma atividade trocando de brincadeira várias vezes, porém a mesma estava ativa nos locais e não ociosa. A permanência total nas praças parece estar relacionada não à manutenção ou a oferta de equipamentos (qualidade e quantidade dos mesmos), mas a fatores como idade da criança, a distância da praça a residência, o tipo de companhia (criança-adulto; criança-criança).

As praças em que as crianças ficaram mais tempo numa mesma atividade foram aquelas que dispunham de uma estrutura mais adequada em termos de oportunidades de brincadeiras, como encontrados na P2 e P3. Estas praças contam com uma gama maior de características positivas quando comparada com as demais. Neste sentido, podemos comparar os resultados encontrados com os achados de Castonguay e Jutras (2008) e Hume et al. (2005), que identificaram que os espaços de brincadeira são destacados pelas crianças pelo número de características positivas de cada local e oportunidades de atividades que eles oferecem.

Mesmo nas praças em que os locais planejados para brincar não eram atrativos, pela escassez e má conservação dos equipamentos, as crianças criaram novas oportunidades de brincadeiras. As crianças se apropriaram e criaram novos significados para os espaços, principalmente os que dispunham de áreas verdes. Os resultados se assemelham aos dados da pesquisa de Rasmussen (2004), que enfatiza que as crianças escolhem, se apropriam e ressignificam os espaços, transformando-os em "espaços da criança".

A presença de vegetação, sobretudo quando abundante, parece estimular a atividade física e mobilidade das crianças, através da exploração do ambiente. Este aspecto, contudo, está fortemente relacionado à qualidade e a quantidade dos equipamentos das praças, tendo que ser analisado de forma integrada: quando a praça apresenta equipamentos variados e em boas condições de uso a influencia da vegetação é menor, ao contrário, quando as praças não apresentam boas condições de uso, a presença de vegetação intervém mais fortemente no tipo de atividade e ocupação do espaço. Neste sentido, os dados se assemelham aos resultados encontrados por Bell et al. (2008), Faber Taylor e Kuo (2009), Janice et al. (2008), Raymundo et al. (2010) e Ridgers et al. (2007), em que a presença de vegetação favorece o contato das crianças com o espaço, oportunizando atividades diferenciadas.
Cabe ressaltar que mesmo impróprias para o uso, as praças são espaços utilizados para as brincadeiras e convívio infantil. Observou-se que os espaços públicos são utilizados mesmo quando apresentam condições vulneráveis quanto a riscos físicos e sociais, demonstrando que estes espaços precisam ser repensados pelo poder público e comunidade em geral.

As características como idade e sexo das crianças apareceram como variáveis que interferem no comportamento de uso das praças e na preferência por brincadeiras realizadas. Tais características pessoais surgem como aspecto relevante, porém, relacionadas às características e oportunidades presentes nos espaços.

Finalizando, os elementos de design disponibilidade e qualidade dos equipamentos, bem como o estado de conservação destes, apresentam-se como aspectos que intervêm no comportamento do brincar infantil e no modo como as crianças usam/ocupam os espaços. Assim um espaço qualificado promove brincadeiras mais variadas, possibilitando o treino de diversas habilidades sociais, físicas, cognitivas e psicológicas. Além disso, a qualidade do espaço favorece a permanência por mais tempo numa mesma atividade e interação promovendo a socialização infantil. A presença de vegetação assume um papel de facilitador no contato das crianças com espaços públicos uma vez que os tornam mais atrativos. Além disso, tal atratividade permite que a criança permaneça por mais tempo brincando, socializando, exercitando, criando, tornando o espaço um cenário de promoção do desenvolvimento saudável. Diante da importância do tema para o desenvolvimento infantil - ou melhor, humano, sugere-se que mais pesquisas possam se empenhar em investigar o potencial dos espaços públicos para tal desenvolvimento.

\section{Referências}

Barbou, A. C. (1999). The impact of playground design on the play behaviors of children with differing levels of physical competence. Early Childhood Research Quarterly, 14(1), 75-98.

Bell, J. F., Wilson, J. S., \& Liu, G. C. (2008). Neighborhood greenness and 2-year changes in body mass index of children and youth. American Journal of Preventive Medicine, 35(6), 547-553.

Bronfenbrenner, U. (1996). A ecologia do desenvolvimento humano: Experimentos naturais e planejados. Porto Alegre, RS: Artes Médicas. (Original publicado em 1979)

Bronfenbrenner, U. (1999). Environments in developmental perspective: Theoretical and operational models. In S. L. Friedman \& T. D. Wacks (Eds.), Measuring environment across the life span: Emerging methods and concepts (pp. 3-28). Washington, DC: American Psychological Association.

Castonguay, G., \& Jutras, S. (2008). Children's appreciation of outdoor places in a poor neighborhood. Journal of Environmental Psychology, 29(1), 101-109. doi: 10.1016/j. jenvp.2008.05.002

Faber Taylor, A., \& Kuo, F. E. (2009). Children with attention deficits concentrate better after walk in the park. Journal of Attention Disorders, 12, 402-409. 
Fedrizzi, B. (2002). A organização especial em pátios escolares grandes e pequenos. In V. Del Rio, C. R. Duarte, \& P. A. Rheingantz (Eds.), Projeto do Lugar: Colaboração entre Psicologia, Arquitetura e Urbanismo (pp. 221-229). Campinas, SP: Editora da Universidade de Campinas.

Fernandes, O. S., \& Elali, G. A. (2008). Reflexões sobre o comportamento infantil em um pátio escolar: O que aprendemos observando as atividades das crianças. Paidéia (Ribeirão Preto), 18(39), 41-52.

Fjùrtoft, I., \& Sageie, J. (2000). The natural environment as a playground for children landscape description and analyses of a natural playscape. Landscape and Urban Planning, 48, 83-97.

Günther, H., Elali, G. A., \& Pinheiro, J. Q. (2008). A abordagem multimétodos em estudos pessoa-ambiente: Características definições e implicações. In J. Q. Pinheiro \& H. Günther (Eds.), Métodos de Pesquisa nos Estudos Pessoa-Ambiente (pp. 369-396). São Paulo, SP: Casa do Psicólogo.

Harada, M. J., Pedreira, M. L., \& Andreotti, J. T. (2003). Segurança com brinquedos de parques infantis: Uma introdução ao problema. Revista Latino-Americana de Enfermagem, 11(3), 383-386.

Herrington, S., \& Studtmann, K. (1998). Landscape interventions: New directions for the design of children's outdoor play environments. Landscape and Urban Planning, 42, 191-205.

Hume, C., Salmon, J., \& Ball, K. (2005). Children's perceptions of their home and neighborhood environments, and their association with objectively measured physical activity: A qualitative and quantitative study. Health Education Research, 20(1), 1-13.

Janice, F. B., Jeffrey, S. W., \& Gilbert, C. L. (2008). Neighborhood greenness and 2-year changes in body mass index of children and youth. American Journal of Preventive Medicine, 35(6), 547-553.

Kuhnen, A. (2009). Comportamento sócio-espaciais e a relação humano-ambiental. In A. Kuhnen, R. M. Cruz, \& E. Takase (Eds.), Interações Pessoa-Ambiente e Saúde (pp. 15-35). São Paulo, SP: Casa do Psicólogo.

Min, B., \& Lee, J. (2006). Children's neighborhood place as a psychological and behavioral domain. Journal of Environmental Psychology, 26, 51-71.

Moore, G. T. (1996). Determining overall space needs in campus child care centers. Campus Child Care News, 11(1), 3-6.

Oliveira, C. (2004). O ambiente urbano e a formação da criança. São Paulo, SP: Aleph.

Pinheiro, J. Q., Elali, G. A., \& Fernandes, O. S. (2008). Observando a interação pessoa-ambiente: Vestígios ambientais e mapeamento comportamental. In J. Q. Pinheiro \& H. Günther (Eds.), Métodos de Pesquisa nos Estudos Pessoa-Ambiente (pp. 75-104). São Paulo, SP: Casa do Psicólogo.

Rasmussen, K. (2004). Places for children - Children's places. Childhood, 11(2), 155-173.

Raymundo, L. S., Kuhnen, A., \& Soares, L. B. (2010). O espaço aberto da educação infantil: Lugar para brincar e desenvolver-se. Psicologia em Revista, 16, 251-270.

Ridgers, N. D., Stratton, G., Fairclough, S. J., \& Twisk, J. W. (2007). Long-term effects of a playground markings and physical structures on children's recess physical activity levels. Preventive Medicine, 44(5), 393-397.

Sager, F., Sperb, T. M., Roazzi, A., \& Martins, M. F. (2003). Avaliação da interação de crianças em pátios de escolas infantis: Uma abordagem da Psicologia Ambiental. Psicologia: Reflexão e Crítica, 16(1), 203-215.
Sommer, R. (1990). Local research. Journal of Social Issues, 46(1), 203-214.

Souza, A. M., \& Vieira, M. L. (2004). Origens históricas da brincadeira. Psicologia Brasil, 2(7), 28-33.

Valentine, G., \& Mckendrick, J. (1997). Children's outdoor play: Exploring parental concerns about children's safety and the changing nature of childhood. Geoforum, 28(2), 219-235.

Wells, N. M. (2000). At home with nature: Effects of "greenness" on children's cognitive functioning. Environment \& Behavior, 32, 775-795.
Recebido: 23/08/2011

$I^{a}$ revisão: $18 / 04 / 2012$

$2^{a}$ revisão: $04 / 06 / 2012$

Aceite final: 19/06/2012 